\title{
MANAGEMENT OF CRISES DURING ANESTHESIA AND SURGERY. PART XVI: HARMS LINKED TO DRUGS ADMINISTERED DURING ANESTHESIA
}

\section{Salam N Asfar ${ }^{@}$ \& Jasim M Salman ${ }^{\#}$}

${ }^{@}$ MB,ChB, MSc, Professor of Anesthesiology, College of Medicine, University of Basrah. "MB,ChB, DA, FICMS, Assist. Prof. \& Consultant Anesthesiologist, College of Medicine, University of Basrah, Basrah, IRAQ.

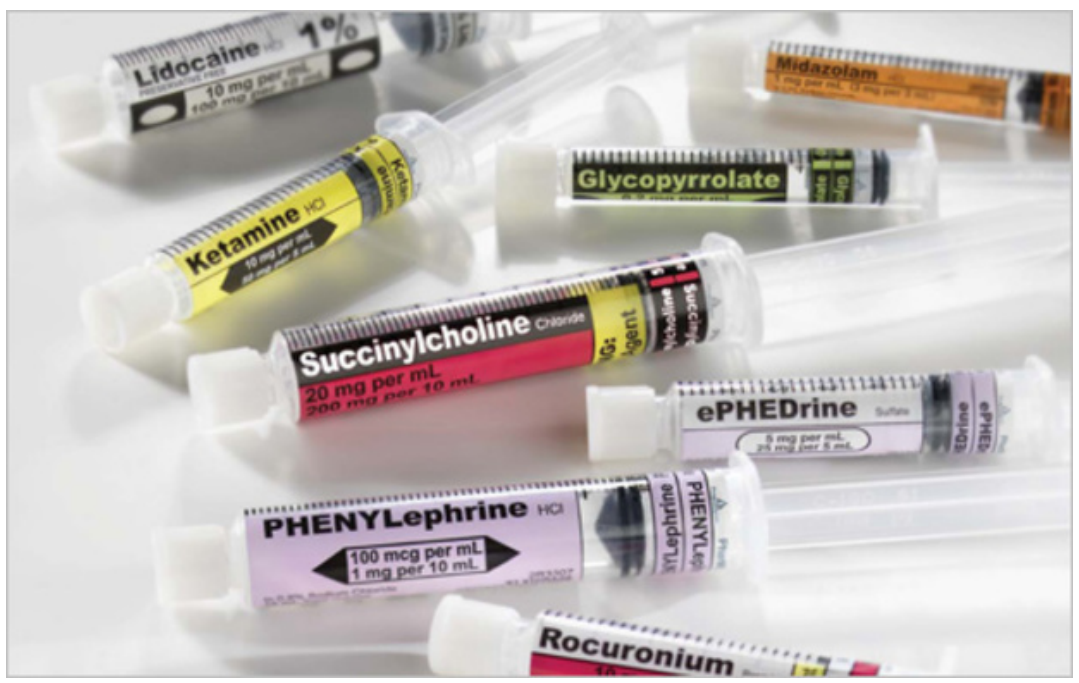

Unpleasant drug incidents are common during medical action. In anesthetic practice, the probability of errors is greater because of more tension and rapidity. Morbidity and even mortality are more expected in the course of anesthesia.

Apart from many hazards that patients are exposed to such as; Biological hazards, Mechanical hazards, Chemical hazards, Physical hazards, and Personal Hazards ${ }^{1}$, it seems that danger of drug problems are more.

The factors that make drug harm to a patient undergoing surgery through general anesthesia includes ${ }^{2}$, .

\section{Problems related to anesthesiologists:}

Error of judgment, Inattention, Haste, Communication problem, Fault of technique complications such as injection into nerve pneumothorax or hematoma formation, Inexperience, Failure to check equipment, Drug label, Inadequate preoperative patient assessment, Fatigue of the anesthesiologist, inadequate or incorrect preoperative patient preparation, Distraction, Unfamiliar environment or equipment, Inadequate assistance, Monitor problem, Pressure to proceed, Surgical team contribution, Staff change, and underestimating patients with high risk. 


\section{Problems related to drug:}

Overdosage, wrong drug, side effects, underdosage, allergy, inappropriate drug, interaction, and contamination.

Incidents related to the administration of drugs are very frequent in anesthetic practice. A drug crisis or medication fault should always be considered as a possible cause of any event arising in association with administration of anesthesia.

\section{Care should be taken in the following if a drug problem occurs ${ }^{4,5}$.}

\section{Emergency check:}

Review all ampoules and syringes, Review all drug labels, Review all vascular access equipment working from fluid source and cannula, Check dilution rates and routes if they are correct, and correlate doses with effects.

Always consider:

Wrong patient and wrong drug, Ampoule or syringe swap, Known allergy, Wrong dose or rate, Wrong diluent or dilution, Wrong time, Wrong route, Malpositioned cannula tip, Empty syringe or bag, Cannula or line are disconnected, blocked or kinked, Flushing syringe containing drug, and Unauthorized person is giving a drug.

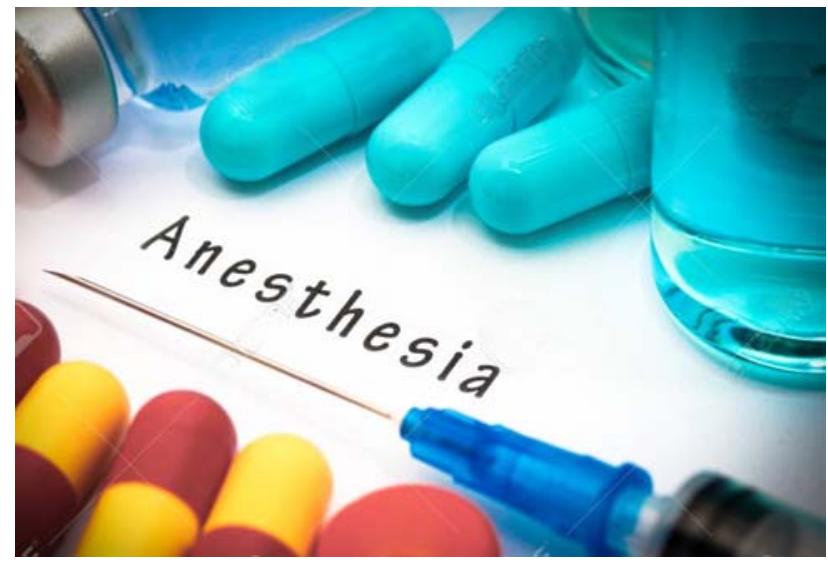

\section{References}

1. Sukhminder Jit Singh Bajwa, and Jasbir Kaur, Risk and safety concerns in anesthesiology practice: The present perspective. Anesth Essays Res. 2012;6 (1): 14-20.

2. Dilip Kothari, Suman Gupta, Chetan Sharma, and Saroj Kothari. Medication error in anaesthesia and critical care: A cause for concern. Indian J Anaesth. 2010 May-Jun; 54(3): 187-192.

3. Mike Stabile, Craig S. Webster, Alan F. Merry. Medication administration in anesthesia. APSF newsletter, 2007; Volume 22, No.3.

4.Beverley A. Orser, Sylvia Hyland, David U. Review article: Improving drug safety for patients undergoing anesthesia and surgery. Canadian Journal of Anesthesia. February 2013, Volume 60, Issue 2, pp 127-135.

5. Paix AD, Bullock MF, Runciman WB, Williamson JA; Crisis management during anaesthesia: problems associated with drug administration during anaesthesia. Qual Saf Health Care 2005;14:e15 (http://www.qshc.com/cgi/content/full/14/3/e15. 